\title{
The Household-Centred Environmental Sanitation approach
}

\author{
Christoph Lüthi, Roland Schertenleib, \\ and Elizabeth Tilley
}

\begin{abstract}
Too often, standardized groupings of sanitation and treatment technologies are imposed in situations where they may not be appropriate. The Household-Centred Environmental Sanitation (HCES) approach instead emphasizes that the needs and means of households should be put first, and a collaborative process involving all stakeholders should steer the planning process.
\end{abstract}

$\mathrm{I}$ n 2007 for the first time in the history of mankind the majority of the world's population is urban. African and Asian cities in particular are growing at break-neck rates. Many, if not most of this new urban population will reside in mushrooming, unplanned and informal settlements or favelas, bidonvilles, chawls or bustees as they are popularly known. In these expansive urban and peri-urban settlements 'onsite sanitation' is the norm. Yet despite on-site low-cost sanitation being the reality for the vast majority of the developing world's urban population,

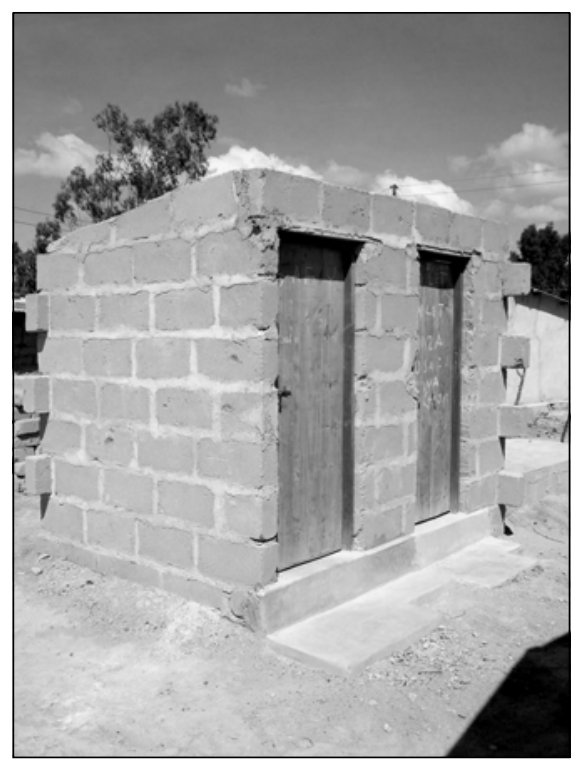

On-site low-cost sanitation is the norm, especially in densely populated informal settlements. much of the focus for policymakers is still on network sewerage and top-down centralized systems designed and implemented without consultation with, and the participation of, stakeholders and beneficiaries.

\section{The case for a change}

There is a need to challenge conventional thinking, and to do so persuasively to the wider international water resources and waste management community, public and private, and especially to professionals and policyand decision-makers. The basis for this need is as follows:

- The past has proven that 'business as usual' cannot provide services for the poor; the rapid rate of urbanization poses particular problems of squalor, human indignity, and the threat of epidemic.

- 'Business as usual' is often not sustainable even in the industrialized world; where sewerage and drainage systems are over-extended and the use of water of drinking quality to transport human excreta is extravagant and wasteful with regard to valuable nutrients.

- Stakeholder involvement is vital to enable ownership and achieve costrecovery.

- There is a lack of integration between the different components of environmental sanitation: excreta, wastewater, solid waste and storm water management. Better use of synergies can lead to more economically sustainable solutions. The pressures of humanity on a fragile water-resource base and the corresponding need for environmental protection and resource conservation, requires that wastewater and nutrients in wastes be recycled and used as a resource.

- The export of industrialized-world models of sanitation to environments characterized by water scarcity and a lack of financial resources is inappropriate and might even increase inequities within a society.

\section{Bellagio Principles}

In the light of these compelling arguments for radical re-thinking, a group of experts met in 2000 in Bellagio, Italy, and suggested that any environmental sanitation system should be based on a set of four basic principles, also known as the 'Bellagio Principles for Sustainable Sanitation':

- Human dignity, quality of life and environmental security at household level should be at the centre of the new approach, which should be responsive and accountable to needs and demands in the local and national setting.

- In line with good governance principles, decision-making should involve participation of all stakeholders, especially the 
consumers and providers of services.

- Waste should be considered a resource, and its management should be holistic and form part of integrated water resources, nutrient flows and waste management processes.

- The domain in which environmental sanitation problems are resolved should be kept to the minimum practicable size (household, community, town, district, catchment, city) and wastes diluted as little as possible.

The Household-Centred Environmental Sanitation (HCES) approach was consequently developed by the Environmental Sanitation Working Group of the Water Supply and Sanitation Collaborative Council (WSSCC). Preliminary guidelines were published in June $2005,{ }^{1}$ targeting public officials and decision-makers and sector specialists.

The HCES approach is a multisectoral approach that places the household and neighbourhood at the core of the planning and implementation process. Decisions on determining the type of environmental sanitation services to be implemented are based on the actual needs and means of the users and are done in close consultation with all stakeholders. Rather than suggesting or promoting one specific solution or technology, the HCES approach suggests a holistic planning process whose key participants are the stakeholders, including those at the household level, especially women, who make the basic decisions on personal hygiene and environmental services. Local government and government agencies respond to the needs by creating an environment which enables the successful implementation of the services identified as the most adequate during the participatory planning process. A further feature is the environmental sustainability concept based on circular resource management systems, where environmental sanitation problems are addressed as closely as possible to their source and an emphasis is placed on resource conservation and waste reduction as it is for instance implemented in ecosan toilets.

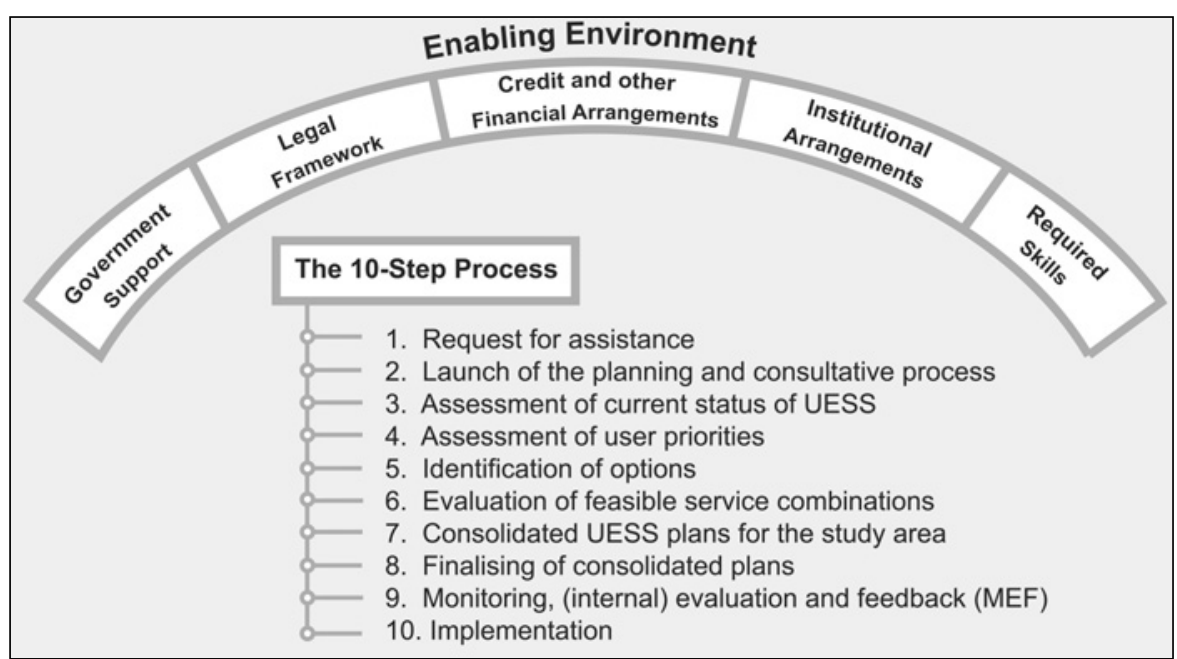

Figure 1: The defining elements of the HCES approach: an enabling environment framework and the 10-step planning process.

\section{Testing the HCES Planning Approach}

In the past year, six testing sites were selected and implementation initiated: two sites in Costa Rica, Central America; one in Burkina Faso, West Africa; two in Kenya and Tanzania, East Africa; and one in Laos, South-East Asia. In the selection of pilot sites, we joined forces with locally anchored institutions, i.e. the Latin American Faculties of Social Sciences (FLACSO) in Costa Rica, the research institution CREPA in West Africa and 'Maji na Ufanisi' (Water and Development), a watsan NGO in Kenya.

So far, as step 2 of the planning process, launching workshops have been held in Costa Rica, Kenya and Burkina Faso, and their results in terms of stakeholder participation and content surpassed our expectations. Participation, reflected by the lively debate and concrete results of the community at large and key stakeholders at national and municipal level, was achieved in all workshops. The following factors largely contributed to the success of the launching workshops:

- a good mix of stakeholders;

- a gender balance in community representation;

- an appropriate space for the community to speak out and voice its concerns;

- careful preparation and detailed organization of the launching event. Successful implementation of the HCES approach requires the dissemination of information to those responsible for improving environmental services, such as municipal officials, urban planners, and policy makers responsible for creating an enabling environment and their training in the use of HCES. To fulfil their new roles, stakeholders need to be provided with information so their capacity to make decisions, and manage services grows.

\section{Compendium of Sanitation Systems}

Currently, a Compendium of Sanitation Systems ('Compendium') is being developed to facilitate a more transparent, participatory approach to Step 5 of the HCES approach: the identification of different options. Classically, sanitation systems have been viewed as 'packages', or groupings of components that work together to move and treat wastewater; a flush toilet, combined sewers, and an activated sludge treatment plant is a common 'package' system in most western cities. In the developing world the common sanitation package is a pit latrine which is pumped out by vacuum trucks and the sludge is left to settle in ponds. These systems, though effective in some situations are too often applied as 'fixall' solutions even in areas for which they are entirely inappropriate.

When systems are designed as groupings of technologies, there is no room for flexibility or adaptation to local customs and needs. By viewing each aspect of the system as an individual component and selecting specific components based on its appropriateness to the geography, culture, economics and wants of the community, a more 


\section{Ecosanitation}

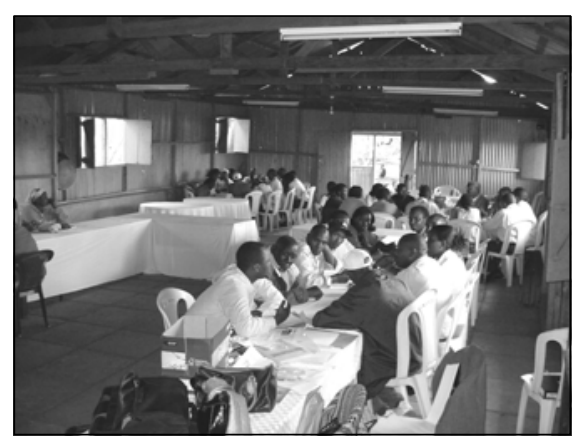

The starting point of the HCES approach is the launching workshop involving key stakeholders in the process.

robust, efficient, and therefore wellmanaged system can be developed.

The Compendium is broken into five sections: User interface, On-site storage, Conveyance, Treatment and residual and Resource recovery. Within each section, a variety of options (between 6 and16) exists; users select one option from each section to build an entire system. The Compendium will allow all stakeholders to participate in the selection process and make informed decisions. Although the options presented are appropriate for ecosan solutions, and decentralized-type systems, a spectrum of options (including options like low-cost or condominium sewers) are also included to present a fair, unbiased list of options from which users can choose.

Certainly, infrastructure improvements based on the HCES approach will take more time to develop than singlesector, capital-intensive projects. The investment in development is justified, however, because the HCES approach offers the one result that previous approaches have been unable to achieve: sustainability.

\section{About the authors}

Christoph Lüthi, Roland Schertenleib, and Elizabeth Tilley are with the Department for Water and Sanitation in Developing Countries (SANDEC), Swiss Federal Institute of Aquatic Science and Technology, Eawag, Switzerland.

\section{References}

1 Eawag/Sandec (2005) 'Household-Centred Environmental Sanitation - Implementing the Bellagio Principles in urban environmental sanitation', Provisional Guideline for Decision-Makers, Eawag/ Sandec, available in English, French and Spanish.

\section{webwatch}

\section{Ecosanitation}

- EcoSanRes: Closing the loop on sanitation

EcoSanRes brings together a variety of resources related to eco-sanitation, from conferences and events, eco-san projects and initiatives, including a global map, and news items, to publications and factsheets, online discussion groups and calls for funding.

http://www.ecosanres.org/

- GTZ Ecological Sanitation In May 2001, GTZ began an international ecosan research and development programme. The website explains the concept of ecological sanitation, the GTZ approach and results from its pilot projects. Interesting links are provided to those working within the international ecosan network, including working groups, universities and the private sector. Links are also provided to the GTZ ecosan newsletter, documents database and recommended reading.

http://www.gtz.de/en/themen/umwelt-infrastruktur/wasser/8524.htm

- Ecological Sanitation at WASTE

Ecosan at WASTE provides information on the technical, financial, environmental, health, socio-cultural, institutional, political and legal aspects that are important for the success of ecosanitation, with an emphasis on urban solutions. It also offers practical examples of sanitation systems from around the world, interesting sanitation-related links, useful publications and profiles of available sanitation experts.

http://www.ecosan.nl/

- Sanitation Connection - Ecological Sanitation This thematic area of the Sanitation Connection website offers a useful introduction to the topic, with frequently asked questions, a list of online publications, and links to other relevant websites. http://www.sanicon.net/titles/topicintro.php3?topicld=17

- Eco-solutions

Eco-solutions promotes and demonstrates community-focused initiatives in water, soil, sanitation and health security. The website describes the related services they can provide, their technological innovations and publications. http://www.eco-solutions.org/

- 'One step closer to sustainable sanitation', Steve Sugden, WaterAid This reports outlines the experiences of an ecological sanitation project in Malawi, reflecting on how the stimulation of demand for eco-san latrines has enhanced the possibilities of developing a sustainable latrine building programme. http://www.wateraid.org/documents/plugin_documents/ revisedecosanitationreportmalawi.pdf

- WELL Factsheet: Ecological Sanitation

One in a series of WELL Factsheets, this provides a clear introduction to the subject, including definitions and history, ecological latrine design, reasons for and against the approach, with key references for those who wish to know more. http://www.lboro.ac.uk/well/resources/fact-sheets/fact-sheets-htm/ Ecological\%20sanitation.htm

- WELL Briefing Note - Should ecological sanitation carry a health warning? This Briefing Note assesses the health risks associated with different stages in the ecological sanitation process, taken from the user's perspective. It focuses on headline facts, pathogen reduction, post latrine handling, hygienic behaviour and overall risk.

http://www.lboro.ac.uk/well/resources/Publications/Briefing\%20Notes/ BN27\%20Ecological\%20sanitation.htm

Compiled by Julie Fisher, Water, Engineering and Development Centre, UK. 